\title{
O ENSINO DA ARTE NA BASE NACIONAL COMUM CURRICULAR (BNCC)
}

\section{ART TEACHING IN THE NATIONAL CURRICULAR COMMON BASE}

\section{LA ENSEÑANZA DEL ARTE EN LA BASE NACIONAL COMÚN CURRICULAR}

\author{
Ana Beatriz Forte Bortolucci \\ Licenciatura em Pedagogia - Faculdades Integradas de Jaú \\ Email: bia_bortolucci@hotmail.com \\ Juliana Valenzola \\ Licenciatura em Pedagogia - Faculdades Integradas de Jaú \\ Email: julianavalenzolajau@ hotmail.com \\ Carla Maria Nicola Coletti \\ Mestra em Educação: Processos de Ensino, Gestão e Inovação \\ Docente das Faculdades Integradas de Jaú \\ Email: carlinhanicola@gmail.com
}

\section{RESUMO}

O ensino de Arte enfrentou diversos obstáculos frente ao reconhecimento enquanto área epistemológica e buscou obter espaços nos normativos que embasam a legislação educacional brasileira, se constituindo enquanto componente curricular obrigatório somente com a homologação da Lei de Diretrizes e Bases da Educação Nacional (LDBN) 9394/96. Entretanto, a autenticação de um novo documento que entrou em vigor no ano de 2020, ocasionando mudanças no currículo brasileiro e consequentemente no ensino da Arte: A Base Nacional Comum Curricular (BNCC). O objetivo desta pesquisa é analisar as possíveis alterações no ensino da Arte com a implantação da BNCC. A metodologia utilizada para construção deste trabalho consistiu em uma revisão bibliográfica, na qual foram selecionados livros, artigos, revistas e redes eletrônicas. Como resultados foi possível constatar a abertura para interpretações errôneas que a BNCC proporciona em comparação aos demais normativos, acarretando em receios e déficits na formação docente. A Arte não deve ser menosprezada na nova estruturação curricular, é preciso repensar esta questão, pois ela contribui para o desenvolvimento pleno do indivíduo, aperfeiçoando sua sensibilidade e criatividade possibilitando um melhor convívio em sociedade, de modo a intervir na mesma maneira autônoma propondo soluções inovadoras que a arte é capaz de proporcionar.

Palavras-chave: Arte. Base Nacional Comum Curricular (BNCC). Formação Docente.

\section{ABSTRACT}

Art theaching faced several obstacles related to the recognition as an epistemological area. It sought to obtain spaces in the norms that support the Brazilian educational legislation, constituting itself as a mandatory curricular component only with the approval of the Law of Guidelines and Bases of National Education (Lei de Diretrizes e Bases da Educação Nacional) 9394/96. However, the authentication of a new document started in the year 2020, causing changes in the Brazilian curriculum and, consequently, in the Art teaching: The National Common Curricular Base (Base Nacional Comum Curricular). This research aims to analyze 
the possible changes in Art teaching with the National Common Curricular Base's implementation. The methodology used to construct this work consisted of a bibliographic review, in which books, articles, magazines, and electronic networks were selected. With this research was possible to verify the openness to erroneous interpretations that the National Common Curricular Base provides compared to the other regulations, causing fears and deficits in teacher formation. Art should not be overlooked in the new curricular structure. It is necessary to rethink this issue, as it contributes to the individual's full development, improving his sensitivity and creativity, enabling a better interaction in society to intervene in the autonomous way proposing innovative solutions that art can provide.

Keywords: Art. National Common Curricular Base. Teacher Education.

\section{RESUMEN}

La asignatura Arte, como área epistemológica, enfrentó a diversos obstáculos reconocidos, como obtener espacios en los normativos que basan la legislación educacional brasileña, constituyéndose como componente curricular obligatorio solamente tras la homologación de la Ley de Directrices y Bases de la Educación Nacional (LDBN 9394/96). Sin embargo, la autenticación de un nuevo documento que ha entrado en vigor en el año 2020, causando cambios en el currículo brasileño y, consecuentemente, en la enseñanza del Arte: La Base Nacional Común Curricular (BNCC). El objetivo de esta investigación es analizar las posibles alteraciones en la enseñanza del Arte con la implantación de la BNCC. La metodología utilizada para la construcción de este trabajo consistió en una revisión bibliográfica en la cual se seleccionaron libros, artículos, revistas y redes electrónicas. Como resultados, fue posible constatar la apertura para interpretaciones erróneas que la BNCC proporciona en comparación con los demás normativos, conllevando recelos y déficits en la formación docente. El Arte no debe ser menospreciada en la nueva estructuración curricular, sino es necesario repensar sobre esa cuestión, porque ella contribuye al desarrollo pleno del individuo, perfeccionando su sensibilidad y creatividad, posibilitando una mejor convivencia social, para que se intervenga en la misma forma autónoma, proponiendo solucciones innovadoras (proporcionadas por la capacidad de esa asignatura).

Palabras clave: Arte. Base Nacional Común Curricular (BNCC). Formación Docente.

\section{INTRODUÇÃO}

O ensino de Arte corresponde a um dos integrantes do currículo brasileiro. Entretanto, seu espaço de conquista é relativamente recente, visto que sua obrigatoriedade de ensino nas escolas fora regulamentada somente pela Lei de Diretrizes e Bases da Educação Nacional 9394/96 (LDB), há 24 anos. (BRASIL,1996).

Deste modo, sua inserção é tida como triunfo para os muitos profissionais da área que ainda relutam contra a visão estereotipada, já que tal componente enfrenta a atribuição de uma visão de caráter recreativo, com a predominância de trabalhos manuais e interpretação de obras.

Todavia, tal percepção tem a possibilidade de serem agravadas com a autenticação e a colocação da práxis do novo documento normativo destinado as escolas de todo o país que entrou em vigor nesse ano de 2020: a Base Nacional Comum Curricular (BNCC). Muitos 
questionamentos foram levantados sobre ela, principalmente no que concerne a Arte. Dentre eles se destacam: a ausência da participação dos educadores na elaboração da proposta, a vinculação de interesses de instituições privadas à lógica do mercado. $\mathrm{O}$ descaso com à sua posição referente a prevalência desmedida de outras áreas e a abertura para a cultura polivalente de formação.

A metodologia utilizada para o desenvolvimento deste estudo consistiu em uma revisão bibliográfica, no qual foram selecionados livros, artigos e revistas em meios eletrônicos. A fim de investigar e explanar os diversos dados, comparações e perspectivas acerca dos aspectos levantados anteriormente. Pois, acredita-se que é possível e imprescindível evitar o equívoco de menosprezar um componente curricular essencial para a agregar em nossa formação proporcionando o senso crítico, exercido de forma autônoma, contribuindo tanto para um melhor convívio social como para consigo mesmo.

\section{AS MUDANÇAS NO ENSINO DA ARTE COM A NOVA BASE NACIONAL COMUM CURRICULAR}

A educação brasileira é um sistema que sofre inúmeras transformações, designando diversos debates sobre a maneira eficaz de como proporcionar a aprendizagem significativa e elevar o índice de qualidade educacional do país. Em vista disso, para que esse fato se concretize há o embasamento que provém de documentos legais e servem como norte de trabalho a fim de revigorar estratégias. Todavia, a Arte não fica isenta dessas modificações legais. Uma das maiores e significativas para o campo curricular foi a fixação da alteração do sexto parágrafo do artigo 26 da LDB 9394/96 em 23 de fevereiro de 2016 da câmara dos deputados, que modifica e define as diretrizes e bases da educação nacional, relativo ao ensino da Arte, conforme relata Peres (2017). A nota dispõe que as Artes Visuais, a Música, a Dança e o Teatro são linguagens de parte Curricular do Ensino da Arte, imposto nos vários níveis da educação básica que apresenta no parágrafo do artigo 26 da mencionada Lei. Porém, ainda que alcançado esse avanço da identificação das linguagens artísticas, o item curricular não é colocado com um próprio espaço de conhecimento da BNCC. No documento de cunho mais recente a Arte integra a Área de Linguagens, juntamente a Língua Portuguesa, Língua Estrangeira e Educação Física. Não se estabelecendo como campo epistemológico próprio e autônomo.

De acordo com Oliveira (2018), o devido fato de o ensino de Arte ser classificado como “Componente Curricular" de Linguagens e não mais "Área de Conhecimento" é algum dos

$$
\text { RELEDUC | ISE | v. } 3 \text { | n. } 1 \text { | dez. } 2020
$$


itens equivocados presentes na BNCC sobre as instituições da educação pública brasileira. $\mathrm{O}$ ensino dessa disciplina passou a não ser obrigatório nas escolas de rede pública estadual, sendo que o documento também deixou por conta da escola a seleção do docente da linguagem específica que se atende por "regente".

É a instituição quem decide a temática da Área Linguagens que será ministrada, assim como também decidirá se quiser conteúdos de Arte nas aulas, e a linguagem artística que será concebida. Nesse modo, podendo ter ou não o componente curricular Arte. Sem profissionais capacitados nas diversas linguagens artísticas, não terá mais as quatro linguagens - Artes Visuais, Dança, Música e Teatro - ou apenas uma como proposta para a formação do docente na instituição, ou pior, presenciar o resgate da Polivalência do "Componente Curricular”, sendo o professor obrigado a dar aula sobre as diversas linguagens sem ter a devida formação. A ideia, como o próprio nome diz "Base" é oferecer educação igualitária para todas as circunstâncias culturais e sociais no Brasil, obtendo ou não uma instrução compensada e não beneficiada conforme essas mesmas circunstâncias culturais e sociais. É considerável expor que é possível ter, um ensino de Arte com aspectos políticos desiguais de acordo com o contexto cultural e social das instituições. Verificando que a Base compromete-se valer tanto para a educação pública como privada (OLIVEIRA, 2018).

Assim sendo, é possível afirmar que isso designaria maior autonomia das escolas que poderá ser exercida de maneira equivocada, no sentido de priorizar ou descartar determinada(s) temática(s) a serem trabalhadas, desvalorizar a formação do profissional não exigindo capacitação adequada e abrir a margem da destituição de seu caráter obrigatório. À vista disso, não há um local coberto por uma área de conhecimento que propicie a percepção do mundo através da sensibilidade. Konder (2002) sinaliza que é fundamental para perceber o mundo, a amplificação dos paradigmas e do descobrimento da proporção poética da vida, dado que a nossa competência de justificar não é o bastante para entender o todo, e a Arte promove uma clareza estética e mais certeira do mundo. Conforme o autor, a razão é "um instrumento precário".

Segundo Konder (2002), a Arte exibe instigações que requer de nós uma extensa ampliação e revisão incessante da razão. Ele atenta que não deve se ter uma desigualdade ao racionalismo em detrimento da sensibilidade, dado que as duas se complementam e contribuem para a captação da realidade, por diversos meios. A conexão com a Arte propicia uma observação flexível e abundante com relação as outras áreas do conhecimento, assim, como 
ampara na compreensão da proporção social que as manifestações artísticas garantem. À vista disso, é permitido verificar o destaque da Arte na formação de crianças, jovens e adultos, em razão de que ela proporciona ao tendente um conhecimento de si que não pode ser obtido apenas pela Ciência.

A Arte ainda entrava diversas lutas contra a visão estereotipada a qual lhe foi imposta, seja como aula destinada a recreação, ou aquela instituída pelo currículo para preencher o tempo. É preciso conscientizar que ela pode auxiliar a desenvolver nosso senso crítico de nosso lado mais humano para atuar na sociedade. Sendo algo que precisa ser trabalhado com todas as modalidades da Educação Básica.

\section{O SURGIMENTO DA BASE NACIONAL COMUM CURRICULAR}

Muitos acreditam que as discussões sobre a formulação de uma base comum para a educação sejam recentes. No entanto, Macedo (2014) aponta que a imposição de que os currículos necessitam de uma base comum em ponto nacional vem desde 1980. A autora também mostra que essa elaboração já ocorreu em diversos países e, o motivo para tal são diversas, conforme os princípios sociopolíticos, econômicos e educacionais. De um modo geral, todos apresentam propostas com o plano de colaborar para a ascensão da democratização e modernização de ensino. De acordo com Macedo (2014) o Ministério da Educação e Cultura (MEC) em 2009 retorna a debater sobre a base curricular comum, gerando o Programa Currículo em Movimento, responsável pela elaboração de currículos destinados a modalidades educacionais da Educação Infantil ao Ensino Médio, com a atuação de associados da comunidade acadêmica do campo do currículo. Em 2014 com a condução do Plano Nacional de Educação (PNE), traz uma mudança entre a BNCC de Diretrizes Nacionais Curriculares (DNC), determinando que a União, os Estados, o Distrito Federal e os Municípios teriam de concordar na definição de introduzir "os direitos e objetivos de aprendizagem e desenvolvimento que configurarão a Base Nacional Comum Curricular do Ensino Fundamental" (BRASIL, 2014 apud MACEDO, 2014).

Foi somente no ano seguinte, em 2015 que a primeira versão da BNCC foi disponibilizada. Entretanto, houve uma grande mobilização de diversos educadores por não obterem participação na elaboração da proposta. Em 2016 e 2017, são apresentadas respectivamente sua segunda e terceira versão, sendo esta última homologada no mesmo ano.

$$
\text { RELEDUC | ISE | v. } 3 \text { | n. } 1 \text { | dez. } 2020
$$


No ano de 2018, foi autenticada a BNCC para a modalidade do Ensino Médio devendo esta entrar em vigor após dois anos de sua legitimação, ou seja, em 2020 (BRASIL, 2018). Macedo (2014) chama a atenção para o desempenho das instituições privadas na direção na produção da BNCC, a autora percebe que estas "agentes sociais privadas" visam intervir nas políticas públicas para a educação com o fim de instituir seus interesses, pretendendo alcançar certo poder sobre os currículos. A autora expõe a ocorrência de várias fundações privadas terem se apoderado do procedimento de debates da BNCC, buscando formar um ideal de ensino numa concepção neoliberal, apontando como remédio de problemas ocasionados pela má gestão do setor público. Realiza-se a palavra de que um currículo comum garantirá a qualidade de ensino, dado que definirá o que será obrigado a ensinar e o que deve ser aprendido, possibilitando uma melhor avaliação dos alunos.

Alves (2014) e Macedo (2014) concordam que a direção da BNCC está sendo inspirada pelos estabelecimentos privados que se propõe à criação de um modelo novo de regulação, que proporcionará o comando de que será ensinado e aprendido. Ao revés de se assegurar um progresso para a educação, o que contaremos é uma contribuição para as desigualdades educacionais, pois, o que a BNCC “tem a oferecer é apenas a tentativa de controle do imponderável da qual depende, não o sucesso da educação, mas a hegemonia do imaginário neoliberal de que ele é parte" (MACEDO, 2014). Desde o seu surgimento a BNCC vem sido acompanhada por uma visão duvidosa. Suas implicações estariam, portanto, atreladas não ao intuito de melhoria educacional, mas sim a instauração velada da classe dominante e seus benefícios. A sua credibilidade era e ainda permanece questionável.

\section{OS PARADIGMAS ENTRE A BNCC E OS PCN}

Ao analisar as implicações da BNCC é imprescindível traçar um paralelo com os Parâmetros Curricular Nacionais (PCN) elaborado há vinte anos, em 1997, afinal ambos fornecem mudanças altamente significativas no sentido de articular teoria e prática por intermédio de suas orientações de implicações pedagógicas. Promovendo assim, uma melhor compreensão de suas complementações e disparidades, ou seja, em quais aspectos dialogam, acrescentam ou se divergem completamente. Á começar pelo caráter que cada documento será instituído, enquanto os PCN servem de instrumento para oferecer norte e suporte ao professor; a BNCC é de caráter normativo, regulamentando todas as instituições de ensino do país. 
Segundo Iavelberg (2018), a forma como a Arte é abordada é distinta em ambos, pois enquanto na BNCC, do $1^{\circ}$ ao $5^{\circ}$ ano do Ensino Fundamental I ela é tida como elemento constituinte da Área de Linguagens, nos PCN foi anexada como disciplina, no qual deve ser trabalhada em correspondência com demais áreas do conhecimento, articulada aos temas transversais e possuindo um documento próprio. Não obstante, a diferença se estende a proporção de como a disciplina é apresentada nesses documentos, ocupando respectivamente, doze páginas $(7 \%)$ em um total de cento e setenta e três páginas e em cento e dezesseis páginas (16\%) em um total de setecentos e dezoito. Sendo assim, é claramente notável uma maior equiparação entre as áreas a serem exploradas nos PCN conforme Iavelberg (2018). Em contrapartida, é possível perceber a exorbitante predominância de algumas matérias em relação as demais na BNCC como: Matemática e Língua Portuguesa, que se apoderam a uma margem de $20 \%$ de destaque. Esse fato está atrelado ao contexto capitalista que vivenciamos no Século XXI, assim como a sociedade teve de se modificar para atender às necessidades do mesmo, a escola assume uma nova responsabilidade de formar sujeitos que sejam aptos e competentes para atender às demandas do mercado de trabalho, resultado dessa maneira, conforme salienta Carvalho (2017 apud IAVELBERG, 2018), na priorização de disciplinas que contribuam para a manutenção e progresso deste quadro, enquanto as demais não se tornam ausentes, mas sim são relegadas.

Consequentemente, é viável afirmar que a Arte é uma das esferas educativas que, por conta do contexto vivenciado e suas exigências articuladas à objetivação de detenção de eficiência e lucro no mercado, vem assumindo caráter secundário e até mesmo terciário, fato que vem contribuindo de alguma forma para o desmerecimento de seu ensino. Porém, seria inviável assegurar que este é o único agente que colabora para a ocorrência desse evento, estando conexo também a ausência da Arte como elemento decisivo nos exames do processo pedagógico de ensino e o estado inerte da determinação de segmentos na BNCC que se constituem em habilidades, competências e unidades temáticas a serem desenvolvidas no decorrer do $1^{\circ}$ ao $5^{\circ}$ ano do Ensino Fundamental I que se distinguem muito pouco entre as suas esferas temáticas. Toma-se como exemplo o fato de as cinco unidades temáticas Artes Visuais, Teatro, Dança, Música e Artes integradas estarem inter-relacionadas ao objeto de conhecimento denominado "Processos de Criação" (IAVELBERG, 2018). A última concepção citada pela autora complementa mais uma diversidade entre a BNCC e os PCN acerca de sua composição. Os PCN utilizam-se de conteúdos subdivididos em seus três eixos de aprendizagem 
significativa (fazer, fruir e refletir), presente na proposta Triangular de Ana Mae Barbosa, em contrapartida a BNCC emprega o termo objeto de conhecimento que está concatenado as habilidades e as competências que são próprias a área da Arte.

Nesta perspectiva, se faz necessário compreender o significado de "competência". Seu conceito perpassa todos os âmbitos do cenário capitalista da atualidade, sendo antes de tudo um objetivo primordial. De acordo com Zabala e Arnau (2010), essa perspectiva adentrou na Educação, no entanto se opõe totalmente a memorização de conteúdos que serve como base e alicerce para o ensino tradicional, pois uma educação mediada por habilidades para que sejam desenvolvidas certas competências que contribuem para a formação de sujeitos capazes de enfrentarem circunstâncias do cotidiano, seja na escola ou no trabalho efetuando o exercício da cidadania.

Iavelberg (2018) cita que é inegável a estreita relação existente entre competências e habilidades, visto que uma é constituída pela outra, respectivamente. $\mathrm{O}$ ato de mobilizar de maneira conjunta diferentes concepções sejam elas de caráter atitudinal, procedimental ou intelectual, o que só ocorre através da mediação de habilidades. Conclui-se que uma competência engloba um conjunto de diferentes habilidades. Contudo, analisar a progressão das habilidades consiste em uma tarefa extremamente enigmática, devido ao seu caráter abrangente de ocorrência em diferentes âmbitos, como: a vivência familiar, o círculo de amigos, o trabalho, etc. Ficando assim, a cargo dos profissionais da educação a função complexa de observar as habilidades através dos trabalhos desenvolvidos dentro da própria sala de aula e deduzir, por meio das hipóteses criadas, as quais competências elas se relacionariam, o que acaba dependendo exclusivamente, nesse caso, da questão do empenho exercido pelo profissional.

A autora ainda salienta que o componente Arte enfrenta outro obstáculo com a BNCC: a indefinição de seus conteúdos, prejudicando a compreensão de quais habilidades serão trabalhadas para constituir determinada competência. $O$ fato se torna ainda mais grave e alarmante ao verificar que isso não ocorre nas demais áreas, pois é um caso exclusivo deste integrante curricular. Ao traçar um paralelo entre $8^{\circ}$ habilidade do $3^{\circ}$ ano de Geografia, EF03GE08 (código alfa numérico correspondente à ordem: etapa educacional, ano, componente curricular e habilidade a ser desenvolvida), articulada ao objeto de conhecimento Produção, Circulação e Consumo e à unidade temática Natureza, Ambientes e Qualidade de vida e a $6^{\circ}$ habilidade em Arte, EF15AR06, desenvolvida no percorrer do $1^{\circ}$ ao $5^{\circ}$ ano do Ensino Fundamental, respectivamente, é possibilitado um melhor entendimento sobre essa divergência: 
Relacionar a produção de lixo doméstico ou da escola aos problemas causados pelo consumo excessivo e construir propostas para o consumo consciente, considerando a ampliação de hábitos, de redução, reuso e reciclagem/descarte de materiais consumidos em casa, na escola e/ou no entorno (BRASIL, 2017, p. 327).

Enquanto a $6^{\circ}$ habilidade de Arte dispõe: "processos de criação e à unidade temática Artes Visuais e foi assim redigida: Dialogar sobre a sua criação e as dos colegas, para alcançar sentidos plurais" (BRASIL, 2017).

Iavelberg (2018) afirma que é notável que esta comparação exemplifique de maneira clara a carência da Arte em relação aos demais componentes, uma vez que não são obtidas ou determinadas com clareza quais conteúdos estariam relacionados a determinadas habilidades. Além de que, isso pode interferir em outra questão causando um efeito contraditório sobre o que propaga a própria BNCC. Afinal, ela possui como principal objetivo a contemplação de ambas as partes que estruturam o currículo: a obrigatória e a diversificada. No entanto, para que isso de fato ocorra é necessário que haja um diálogo do segmento diversificado com os conteúdos e metodologias que compõem o obrigatório, o que pode suceder em um grande empecilho na esfera artística, devido a indeterminação dos conteúdos citada e exemplificada anteriormente.

As consequências balizam não somente sobre as questões gerais do ensino da Arte, como também no exercício de trabalhar as peculiaridades, sejam elas de nível local, regional ou nacional fortificando o respeito pela diversidade cultural brasileira. Portanto, exige uma certa autonomia do corpo escolar para seletar os conteúdos, especificamente de professores, que dependem de seu empenho profissional para contribuir com a garantia de um ensino de qualidade aos estudantes ou fortalecer ainda mais as desigualdades em termos de aprendizagem.

É possível afirmar, dessa forma que os PCN e a BNCC, são semelhantes no sentido de conduzir a prática pedagógica da sala de aula, porém são divergentes em aspectos como: caráter constituinte, termologia, determinação de segmentos e predominância das disciplinas. Podendo a substituição de um pelo o outro, ser nocivo ao Ensino da Arte.

\section{A POSIÇÃO DA ARTE NA BNCC E A VISÃO CRÍTICA DOS ARTE-EDUCADORES}

De acordo com Peres (2017), a Arte como integrante dentro da Área de Linguagem, corre o risco de se converter em apenas uma disciplina secundária que auxiliará a entender determinado conteúdo de Literatura ou Língua Portuguesa, propiciando na indiferença de seus

$$
\text { RELEDUC | ISE | v. } 3 \text { | n. } 1 \text { | dez. } 2020
$$


assuntos próprios que auxiliam na reflexão e na crítica de itens artístico-culturais localizados em vários momentos históricos e em diversos contextos. As Linguagens Artísticas (Artes Visuais, Dança, Música e Teatro) no documento da BNCC são marcadas como subcomponentes do componente Arte, concedendo espaço para interpretações equivocadas e para a volta da polivalência, alegando a imposição do reconhecimento do trabalho interdisciplinar. Após o debate da colocação da Arte na BNCC no Congresso Nacional da Federação De Arte Educadores do Brasil (CONFAEB) no ofício executado pelos Arte-Educadores, há a acusação de que o Componente Curricular Arte foi infame, segundo o autor, em diferença com os demais componentes. Na declaração, há apenas onze páginas para o aparecimento do Componente Curricular Arte, ao mesmo tempo em que os outros demais têm entre vinte e trinta páginas, o que testemunha uma visão superficial da Arte e mostra o que estão dando vantagem no Currículo.

A atenção que Konder (2002) nos remete é para a ocorrência de que a Arte não está liberta da ideologia, mas que ela oportuniza uma superação fracionária das alterações ideológicas por meio de "obras de Arte bem-sucedidas". Essa ultrapassagem ideológica somente é viável através de um oficio artístico-pedagógico resistente, no qual se possa avistar os vestígios da ideologia na prática educativa e sua poética. Referente ao componente curricular Arte presente na BNCC é possível notar que sua concepção é de uma área de conhecimento implicada com a ideologia dos grupos dominantes, que delimita à pura expressão livre, sem o pensamento de oportunizar aos alunos um conhecimento mais sólido da forma na Arte, isto é, os conteúdos constitutivos do recurso artístico. Desta forma, os alunos terão uma formação reduzida que não auxiliará para o entendimento crítico da Arte e da sociedade (KONDER, 2002).

Foi encaminhado pela Federação de Arte-Educadores do Brasil para à Comissão de elaboração da BNCC, do componente Arte, um documento com as críticas principais ao de 2018. De acordo Peres (2017), as indagações e os requisitos da comunidade de Arte-Educadores não foram encarados. Essa circunstância criou grande desagrado entre os profissionais na disputa pelo espaço e reconhecimento da Arte no currículo escolar. Algumas autoridades presentes na criação da BNCC, do componente Arte, solicitaram isolamento e exclusão de seus nomes da última versão do ofício, por se sentirem usados para validar o método. Não possuíram abertura para que pudessem representar sua comunidade disciplinar e nem a chance de conceber as principais exigências da categoria, sendo desconsideradas palavras de muitos educadores. $\mathrm{O}$ 
último item da imposição destaca para a preocupação com a formação de docentes em Arte em licenciaturas de linguagens artísticas específicas. A preocupação está na chance da volta da conhecida formação polivalente, que pretende a atuação de forma superficial e destituída de reflexão crítica, como acontecia na época da Ditadura Militar (PERES, 2017). Para Barbosa (2016), seria nada menos que uma tentativa camuflada de transplantar o modelo americano em nossas escolas, ignorando nossas peculiaridades e tendo em vista a contenção de gastos, uma estratégia resgatada do período da ditadura militar.

Equitativamente, uma das responsáveis pela elaboração dos PCN, Iavelberg (2018) também se opõe à Medida Provisória. A autora defende que a aplicação não contribuirá para a solução de problemas característicos do nosso sistema como a evasão e a aprendizagem abaixo da média, pelo contrário, pode vir a agravar um quadro ainda mais grave: a inibição de um aluno indagador, totalmente alienado e subordinado a prática tecnicista tanto mercadológica como educacional.

Tal aspecto é alarmante no que concerne à Arte, visto que, tendo sua obrigatoriedade destituída na modalidade do Ensino Médio, fica dependente do interesse dos próprios alunos em optar por frequentá-la ou não:

[...] Restringe a obrigatoriedade do ensino da Arte e da educação física à educação infantil e ao ensino fundamental, tornando-as facultativas no Ensino médio [...] O currículo do Ensino médio será composto pela Base Nacional Comum Curricular - BNCC e por itinerários formativos específicos definidos em cada sistema de ensino e com ênfase nas áreas de linguagens, matemática, ciências da natureza, ciências humanas e formação técnica e profissional [...] (BRASIL, 2016, p. 2, grifo nosso).

Conforme já retratado, não houve o envolvimento dos Arte-Educadores na elaboração do documento, inibindo suas vivências e necessidades presenciadas em sala de aula, tornando a aplicação do que a declaração expõe algo vago, encontrando dificuldades em como transplantar isso na prática, ou seja, como ensinar Arte. Fica a cargo do docente, inclusive, procurar estratégias com o propósito de atrair o aluno para cursar as aulas do componente curricular em pauta.

\section{CONSIDERAÇÕES FINAIS}

As mudanças na sociedade estão inteiramente atreladas a realidade na qual se é vivenciada, surgindo, desta maneira novas demandas para serem supridas. Consequentemente, 
tal responsabilidade é imposta a escola, esta, deve não só entender as necessidades cruciais do século XXI, como preparar os indivíduos para sua atuação na sociedade.

Contudo, na tentativa de acompanhar essas exigências, vários deslizes podem ser gerados. É fato que o Brasil requer uma base nacional comum, porém que seja democrática e aberta à participação de educadores de ambos os setores, pois a educação tem a incumbência de inibir a prática tecnicista que favorece somente determinada classe. Sendo assim, a estruturação em habilidades e competências presentes na BNCC também contribui com a lógica de mercado.

Além disso, a prática artística pode ser prejudicada, principalmente, em aspectos de valorização. Pois, o documento proporciona uma abertura para a cultura polivalente de formação, podendo o professor lecionar sobre as diversas linguagens sem ter a formação específica, ficando assim, o questionamento se estes são e estão, de fato, preparados para ministrar as aulas de maneira adequada ou se limitarão a improvisos didáticas esvaziados de intencionalidade e significado.

A substituição dos PCN pelo novo normativo é, sobretudo, um dos motivos de receio de muitos educadores, devido as divergências entre ambos sobre a Arte. Entretanto, o componente curricular parece ser contemplado de maneira mais adequada nos PCN, pois este apresenta um livro próprio da Arte e adota a concepção de ensino fundamentada nos três eixos da Abordagem Triangular de Ana Mae Barbosa: Fazer, Fruir e Refletir. Ou seja, ao contrário da BNCC, consiste na experiência voltada para o cotidiano e a criticidade.

Não obstante, a obrigatoriedade do ensino de Arte é exonerada na modalidade educacional do Ensino Médio, cuja medida pode interferir de maneira negativa e determinante no desenvolvimento do indivíduo. Afinal, a prática artística permite que o aluno desenvolva sua identidade e autoestima, trabalhe conduzindo suas tensões e sentimentos, potencializando suas percepções, condições estas que influirão na aprendizagem, na conexão com o próprio eu e com o mundo. A pessoa que aperfeiçoa sua sensibilidade artística e estética tem a capacidade de lidar melhor com suas emoções e tem autoconfiança, estando apto para estar e atuar sobre o mundo que necessita de seres humanos críticos, criativos e inovadores.

Estas características, ironicamente, são fatores que podem ser determinantes para valorização das empresas e, consequentemente, o aumento de sua produtividade, tendo em vista que elas procuram justamente funcionários que solucionam problemas de maneira eficaz e veloz. 
Logo, a Arte também adquire um papel extremamente relevante para a formação do sujeito e o desenvolvimento de suas aptidões, não devendo ser menosprezada em detrimento das demais áreas curriculares. É incontestável que o país requer uma mudança em seu setor educacional que vise o acesso de todos os cidadãos a escola. Todavia, a prioridade não se restringe apenas em atender uma quantidade maior de alunos e sim a qualidade do ensino ofertado, sendo este, prejudicado ao não favorecer o desenvolvimento da reflexão crítica, culminando no processo retrógado epistemológico e social.

\section{REFERÊNCIAS}

ALVES, Nilda. PNE, Base Nacional Comum Curricular (BNCC) e os cotidianos das escolas: relações possíveis?.In: AGUIR, Márcia Angela da Silva; DOURADO, Luiz Fernandes. (Orgs.). A BNCC na contramão do PNE 2014-2024: Avaliação e perspectivas.Recife: ANPAE,2018.p.44-58. Disponível em: http://www.anpae.org.br/BibliotecaVirtual/4-Publicac oes/BNCC-VERSAO-FINAL.pdf. Acesso em: 25 maio. 2019.

BARBOSA, Ana Mae. Era uma vez... a obrigatoriedade das Artes no currículo do Ensino Médio. In: Revista Select Arte e cultura contemporânea, edição 33, p.40, 2016. Disponível em: https://issuu.com/editora3/docs/docs/select_33_ok. Acesso em: 11 maio. 2019.

BRASIL. Ministério da Educação. Base Nacional Comum Curricular: Histórico, 2018. Disponível em: http://basenacionalcomum.mec.gov.br/historico. Acesso em: 15 maio. 2019.

BRASIL. Governo Federal. Base Nacional Comum Curricular: Fundamentos Pedagógicos e Estrutura Geral da BNCC: versão 3, Brasília, 2017. Disponível em: http://basenacionalcomu m.mec.gov.br/images/BNCC_publicacao.pdf. Acesso em: 12 jul. 2018.

BRASIL. Governo Federal. Medida Provisória n 746 de 22 de setembro de 2016.

Disponível em: https://www.congressonacional.leg.br/materias/medidas-provisorias/-/mpv/12 6992.Acesso em :23 fev. 2019.

BRASIL. Lei 9.394, de 20 de dezembro de 1996. Estabelece as Diretrizes e Bases da Educação Nacional. Disponível em: www.planalto.gov.br/ccivil_03/leis/L9394.htm. Acesso em: 03 dez. 2018.

IAVELBERG, Rosa. A Base Nacional Curricular Comum e a formação dos professores de Arte. Revista Horizontes, Bragança Paulista, v.36, n.1, p. 74-34, jan. 2018. Disponível em: https://revistahorizontes.usf.edu.br/horizontes/article/view/576. Acesso em: 12 jul. 2018.

KONDER, Leandro. A questão da ideologia. São Paulo: Companhia das Letras, 2002. 
MACEDO, Elizabeth. Base Nacional Curricular Comum: novas formas de sociabilidade produzindo sentidos para educação. Revista e-Curriculum, São Paulo, v. 12, n. 03 p. 1530$1555 \mathrm{out} / \mathrm{dez} 2014$.

OLIVEIRA, Marcos Antônio Bessa. A Base Nacional Comum Curricular: Ensino de Arte nas escolas, ainda é uma coisa possível? In:JORNADA BRASILEIRA DE EDUCAÇÃO E LINGUAGEM, 3., 2018, Campo Grande, Anais... Campo Grande: UEMS, 2018. Disponível em: https://anaisonline.uems.br/index.php/jornadaeducacao/article/dowload/4862/4890. Acesso em: 03 dez. 2018.

PERES, José Roberto. Questões atuais do Ensino de Arte no Brasil: O lugar da Arte na Base Nacional Comum Curricular.Revista Departamento de Desenho e Artes Visuais. Rio de Janeiro, v.1, n.1, 2017. Disponível em: https://www.cp2.g12.br/ojs/inde x/php/revistaddav/article/dowload/1163/859.Acesso em: 12 jul. 2018.

ZABALA, Antoni; ARNAU; Laia. Como aprender e ensinar competências. São Paulo: Artmed, 2010. 